УДК:539.216:539.213:539.264

DOI: $10.17308 / \mathrm{kcmf} .2019 .21 / 724$

Поступила в редакцию 29.12.2018

Подписана в печать 15.02.2019

\title{
СТРУКТУРА И СВОЙСТВА НАНОПОРИСТЫХ АНОДНЫХ ОКСИДНЫХ ПЛЕНОК НА АЛЮМИНИДЕ ТИТАНА
}

\author{
(C) 2019 К. В. Степанова*1, Н. М. Яковлева ${ }^{1}$, А. Н. Кокатев ${ }^{1}$, Х. Петтерссон ${ }^{2}$ \\ ${ }^{1}$ Петрозаводский государственный университет \\ пр. Ленина, 33, 185910 Петрозаводск, Республика Карелия, Российская Федерация \\ ${ }^{2}$ Университет г. Хальмштад \\ SE-302-50 Halmstad, Sweden
}

\begin{abstract}
АННОТАЦИЯ. Работа посвящена обобщению результатов исследования анодирования алюминида титана ( $\gamma$-TiAl) во фторсодержащих электролитах. Установлены оптимальные условия анодирования, приводящие к формированию самоорганизованных нанопористых анодных оксидных пленок (АОП) на поверхности образцов сплава Ti-40 wt. \% Al. Показано, что при оптимальных условиях образуются рентгеноаморфные оксидные пленки гетерогенного состава $\left(\mathrm{Al}_{2} \mathrm{O}_{3}: \mathrm{TiO}_{2} \cong 1: 1\right)$ с размерами пор в диапазоне от 40 до 80 нм. Полученные результаты свидетельствуют о перспективности применения анодного наноструктурирования порошков Ti-40 wt. \% Al для получения фотокаталитически активных материалов с расширенным до видимого света спектральным диапазоном поглощения.
\end{abstract}

Ключевые слова: анодирование, нанопористые, оксидные пленки, порошковый сплав, алюминид титана, гетерогенный, фотокаталитическая активность.

\section{ВВЕДЕНИЕ}

В настоящее время ведется интенсивный поиск материалов, проявляющих фотокаталитическую активность под действием излучения видимого диапазона [1]. Весьма перспективно использование нанокристаллического диоксида титана $\left(\mathrm{TiO}_{2}\right)$, являющегося полупроводником с шириной запрещенной зоны (33) $E_{g}=3.0-3.4 \mathrm{eV}$, проявляющего фотокаталитическую активность под действием ультрафиолетового (УФ) излучения [2]. Для уменьшения рекомбинации фотовозбужденных электронно-дырочных пар как на поверхности, так и в объеме нанокристаллического $\mathrm{TiO}_{2}$ [3-6], в частности, предлагается использование композитных систем на основе $\mathrm{TiO}_{2}$ с многокомпонентными или многофазными гетеропереходами. Так, в последние годы особое внимание уделяется исследованиям зонной структуры и фотокаталитических свойств многокомпонентных материалов, получаемых обычно с помощью зольгель процесса и содержащих наряду с нанокристаллическим $\mathrm{TiO}_{2}$ другие полупроводники $\left(\mathrm{CdS}, \mathrm{SnO}_{2}\right.$, $\left.\mathrm{ZnO}, \mathrm{WO}_{3}\right)$ или диэлектрики $\left(\mathrm{Al}_{2} \mathrm{O}_{3}\right)$ [7-11]. *

Также выполняются исследования фотокаталитических свойств самоорганизованного нанотруб-

$\triangle$ Степанова Кристина Вячеславовна,

e-mail: lady.cristin4ik@yandex.ru чатого анодного $\mathrm{TiO}_{2}$, формируемого непосредственно на поверхности титана [6], что является преимуществом перед нанокристаллическим $\mathrm{TiO}_{2}$, получаемым золь-гель методом. Выдвинуты предположения [6], что термическая кристаллизация аморфных анодных оксидов титана, приводящая к образованию анатаза при сохранении нанотрубчатого строения, и последующее допирование наночастицами благородных металлов должны способствовать сенсибилизации фотокатализатора из нанотрубчатого анодного оксида титана (НTAOT) к видимому свету.

Известно [12], что алюминид титана $\gamma$-TiAl (от 33 до 46 wt. \% Al) обладает жаропрочностью и жаростойкостью, сравнимой с никелевыми суперсплавами, причем предварительное нанесение на его поверхность защитных покрытий увеличивает температурный интервал эксплуатации до 1073-1173 К. Учитывая сложность предлагаемых технологий получения таких покрытий, разработка более простых методов является актуальной проблемой для реализации высокотемпературных применений $\gamma$-TiAl. B работах $[13,14]$ была показана возможность получения самоорганизованных оксидов с нанопористой или нанотрубчатой мезоструктурой (в зависимости от соотношения $\mathrm{Al}$ и $\mathrm{Ti}$ ) с помощью элект- 
рохимического анодирования алюминидов титана в $10 \% \mathrm{H}_{2} \mathrm{SO}_{4}+0.15 \%$ HF. Авторы [13] показали, что формирующаяся на поверхности $\gamma$-TiAl нанопористая пленка состоит из оксидов $\mathrm{Al}_{2} \mathrm{O}_{3}$ и $\mathrm{TiO}_{2}$ в примерно равном соотношении.

Согласно [7], присутствие аморфного $\mathrm{Al}_{2} \mathrm{O}_{3}$, содержащего большое количество дефектов, связанных с кислородными вакансиями, ловушками электронов и дырок, должно способствовать появлению дополнительных межзонных переходов электронов и дырок, а соответственно, и расширению спектрального диапазона фотокаталитической активности до видимой области. Отсюда следует, что изучение возможностей изготовления фотокатализаторов на основе самоорганизованных пористых или трубчатых пленок гетерогенного состава, полученных анодированием интерметаллидов системы TiAl, является весьма актуальным. Особый интерес представляет исследование анодирования образцов из спеченных порошков TiAl, изначально имеющих высокую удельную поверхность. Дальнейшая модификация поверхности микрочастиц порошка анодированием, приводящая к росту наноструктурированной оксидной пленки, должна увеличить удельную поверхность, а соответственно, улучшить биосовместимость, каталитическую и фотокаталитическую активность, а также жаростойкость и жаропрочность материала.

Ранее, при изучении процесса анодирования спеченных порошков TiAl нами было установлено $[15,16]$, что в результате анодирования в $10 \%$ $\mathrm{H}_{2} \mathrm{SO}_{4}+0.15 \%$ НF при $j_{a}=0.2 \mathrm{~mA} / \mathrm{cm}^{2}$ в течение $85 \min \left(T=T_{\text {комн }}\right)$ на поверхности микрочастиц порошка формируются рентгеноаморфные нанопористые анодные оксидные пленки (АОП) гетерогенного состава $\left(\mathrm{TiO}_{2}: \mathrm{Al}_{2} \mathrm{O}_{3} \cong 1: 1\right)$. Особенности проведения процесса анодирования описаны ранее в [15-18].

Настоящая статья посвящена обобщению результатов исследований анодирования алюминида титана (Ti-40 wt. \% Al) во фторсодержащих электролитах и оценке фотокаталитической активности полученных нанопористых оксидных пленок гетерогенного состава.

\section{ЭКСПЕРИМЕНТАЛЬНАЯ ЧАСТЬ}

Объекты и методы исследования. Объектами исследования являлись оксидные пленки, сформированные анодированием в растворах $10 \%$ $\mathrm{H}_{2} \mathrm{SO}_{4}+0.15 \% \mathrm{HF}$ и в $\mathrm{C}_{2} \mathrm{H}_{6} \mathrm{O}_{2}+0.25 \% \mathrm{NH}_{4} \mathrm{~F}$ двух групп образцов. Группа I представляла собой пластинки, нарезанные из слитков, а группа II пред- ставляла собой спеченные порошковые образцы с удельной поверхностью $1600 \mathrm{~cm}^{2} / \mathrm{g}$ сплава Ті40 wt. \% Al. Кроме того, дополнительно выполнялось анодирование образцов Al и Ti (BT1-00) фольги.

Анодирование образцов группы I осуществлялось в $10 \% \mathrm{H}_{2} \mathrm{SO}_{4}+0.15 \% \mathrm{HF}$ (Э-1) при напряжении $U_{a}=20 \mathrm{~V}$, а в $\mathrm{C}_{2} \mathrm{O}_{2} \mathrm{H}_{6}+0.25 \% \mathrm{NH}_{4} \mathrm{~F}$ (Э-2) при $U_{a}=28 \mathrm{~V}$, а образцы группы II анодировались при следующих условиях: электролит Э-1-гальваностатический режим (ГСР) при $j_{a}=0.2 \mathrm{~mA} / \mathrm{cm}^{2}$; электролит Э-2- вольтстатический режим (ВСР) при $U_{a}=60 \mathrm{~V}$. Все образцы анодировались при комнатной температуре. Условия анодирования выбирались в соответствии с [15].

Структура и морфология объектов исследовались методами сканирующей электронной микроскопии (JEOL JSM-6480LV, FEI Nova NanoLab 600) и дифракции рентгеновских лучей (ARL X'TRA, $\mathrm{Cu} K_{\alpha 1}$ излучение). Особенности методики эксперимента и обработки данных описаны в работах [15-20].

Состав поверхности образцов группы I изучен методом рентгеноэлектронной спектроскопии (РЭС). Рентгеноэлектронные спектры получали с участков поверхности диаметром $\sim 5 \mathrm{~mm}$, глубина анализа составляла $~ 3 \mathrm{~nm}$. Из зависимостей интенсивности излучения от энергии связи определялся элементный состав поверхности и концентрация элементов поверхностного и приповерхностного слоя.

Элементный состав образцов оценивался с помощью энергодисперсионного рентгеновского анализа электронов (ЭДСА). Сбор данных проводился для нескольких участков, выбранных на предварительно полученном СЭМ-изображении поверхности, с последующим количественным анализом. Для анодированных образцов группы I толщина оценивалась по степени поглощения рентгеновских лучей (РСА). Для этого регистрировались распределения интенсивности рассеяния рентгеновских лучей $I(2 \theta)$ образцами до и после анодирования в диапазоне углов $2 \theta=15-90^{\circ}$ с шагом $\Delta \theta=0.05^{\circ}$.

Фотокаталитическая активность образцов группы II изучалась в модельной реакции разложения метилового оранжевого (МO) [21-26] с помощью специально разработанной установки под действием видимого излучения (лампа ДРИ 250-5, $\left.\lambda=420-700 \mathrm{~nm}, I=50 \mathrm{~mW} / \mathrm{cm}^{2}\right)$. Исходная концентрация раствора МО была выбрана равной $C_{\text {о, ви }}=5 \mathrm{mg} / \mathrm{l}$ в соответствии со значением, использованным в ряде работ $[23,25]$. Предварительно 
выполнялось измельчение образцов, исследуемый порошок представлял собой совокупность микрочастиц размером от 1 до $20 \mu \mathrm{m}$, покрытых нанопористой оксидной пленкой [15]. Растворы МО перемешивали с исследуемыми порошками с применением барботирования. Для равномерного распределения порошка в растворе и установления равновесия между адсорбцией и десорбцией $[22,23]$ сначала проводили темновое перемешивание в течение 30 минут. Затем осуществляли отбор проб раствора каждый час в течение 7 часов облучения. После этого пробы фильтровали и с помощью спектрофотометра ПЭ-5300ВИ измеряли для каждой пробы зависимости оптической плотности $A(\lambda)$ и коэффициента пропускания $T(\lambda)$ раствора в диапазоне $\lambda=(320-600) \mathrm{nm}$, поскольку светопоглощение МО лежит именно в этом интервале длин волн [24]. Предварительно регистрировалась $A(\lambda)$ исходного раствора МО. Концентрацию $C_{x}$ МО в пробах определяли методом стандартного раствора, также рассчитывали величину конверсии МО.

Оценка оптической ширины запрещенной зоны $\left(E_{g}\right)$ титаноксидной компоненты выполнялась путем определения края собственного поглощения $\left(\lambda_{\text {гр }}\right)$ методом оптической спектрофотометрии (спектрофотометр ПЭ-5300ВИ). Параллельно аналогичные измерения были выполнены для отделенных от подложки нанотрубчатых анодных оксидов титана (НТАОТ) толщиной $40 \mu \mathrm{m}$, сформированных анодированием титана в $\mathrm{C}_{2} \mathrm{O}_{2} \mathrm{H}_{6}+0.25 \% \mathrm{NH}_{4} \mathrm{~F}$. Методика анодирования подробно описана в [20].

\section{РЕЗУЛЬТАТЫ И ИХ ОБСУЖДЕНИЕ}

\section{Анодирование образцов I группы}

Методом СЭМ было установлено, что поверхность образцов группы I до анодирования является достаточно однородной. ЭДСА элементного состава образца показал, что он соответствует Ti-40 wt.\% Al. На дифрактограммах образцов до анодирования присутствовали брэгговские отражения, соответствующие фазе $\gamma$-TiAl, а также отмечались следы фазы TiAl.

Кривые $j_{a}(t)$, полученные при анодировании образцов сплава Ti-40 wt. \% Al, а также $\mathrm{Al}$, Ti с применением условий процесса, предложенных в работе [13]: электролит Э-1, $T_{\mathrm{a}}=293 \mathrm{~K}, U_{\mathrm{a}}=20 \mathrm{~V}, 20 \mathrm{~min}$ показаны на рис. 1. Ход $j_{a}(t)$ для всех исследованных образцов аналогичен и соответствует типичному для формирования самоорганизованных наноструктурированных оксидных пленок $[18,27]$. Необходимо отметить, что величина стационарного тока при анодировании сплава практически в два раза превышает соответствующее значение для Ті и в несколько раз ниже величины, полученной при анодировании Al. Величина тока стационарного роста изменяется в следующей последовательности: $j_{a}^{\mathrm{Ti}} \cong 1.2 \mathrm{~mA} / \mathrm{cm}^{2} ; j_{a}^{\mathrm{Ti}-\mathrm{Al}} \cong 2.4 \mathrm{~mA} / \mathrm{cm}^{2}$; $j_{a}^{\mathrm{Al}} \cong 16 \mathrm{~mA} / \mathrm{cm}^{2}$. Полученные значения свидетельствуют о том, что при анодировании $\mathrm{Ti}, \mathrm{Al}$ и $\mathrm{Ti}-$ $\mathrm{Al}$ в растворе $10 \% \mathrm{H}_{2} \mathrm{SO}_{4}+0.15 \% \mathrm{HF}$ имеет место разное соотношение процессов роста и растворения АОП.

На рис. 2 представлены кривые $U_{a}(t)$, полученные при ГСР-анодировании и кривые $j_{a}(t)$ при ВСР-анодировании образцов в электролите Э-2. На основе анализа зависимостей $U_{a}(t)$ и $j_{a}(t)$, полученных при различных условиях процесса, были выбраны оптимальные условия анодирования, приводящие к формированию нанопористых АОП на поверхности образцов $\gamma$-TiAl (группа I). Так, было установлено, что анодирование в $10 \% \mathrm{H}_{2} \mathrm{SO}_{4}+0.15 \% \mathrm{HF}$ при напряжении $U_{a}=20 \mathrm{~V}$ (рис. 1), а в $\mathrm{C}_{2} \mathrm{O}_{2} \mathrm{H}_{6}+0.25 \% \mathrm{NH}_{4} \mathrm{~F}$ при $U_{a}^{a}=28 \mathrm{~V}$ (рис. 2) обеспечивает типичный ход $U_{a}(t)$ и $j_{a}(t)$, характерный для формирования нанопористых / нанотрубчатых АОП.

Как следует из вида изображений поверхности образцов группы I, анодированных в Э1 при оптимальных условиях, на поверхности Ti-40 wt. \% Al образуется нанопористая АОП толщиной до $\delta \sim 500 \mathrm{~nm}$ с средним эффективным диаметром $<d_{\text {п }}>\cong(50 \pm 10) \mathrm{nm}$ (рис. $\left.3 a\right)$.

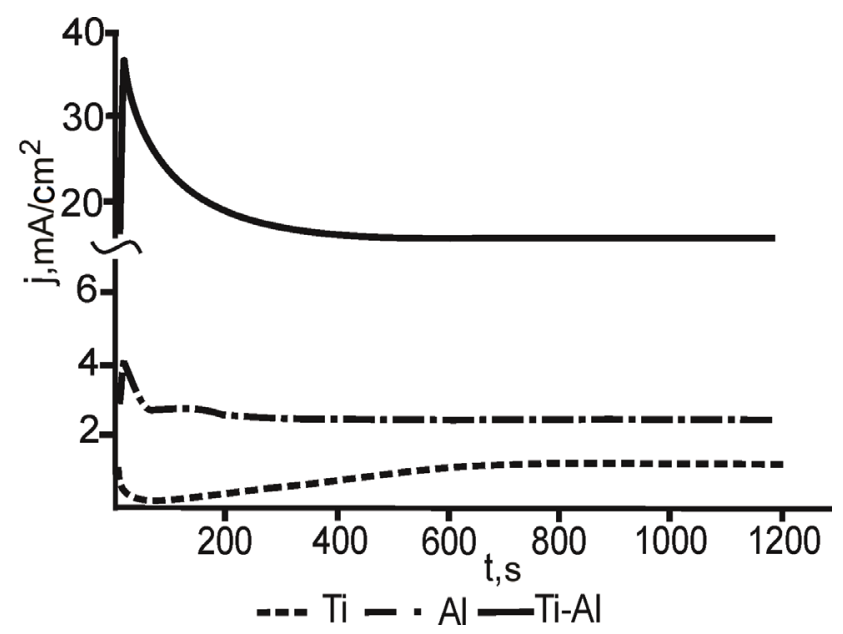

Рис. 1. Кривые $j_{a}(t)$, полученные при вольтстатическом анодировании $\mathrm{Ti}, \mathrm{Al}$ и сплава Ti-40 вес. \% $\mathrm{Al}$ в $10 \% \mathrm{H}_{2} \mathrm{SO}_{4}+0.15 \% \mathrm{HF}, T_{\mathrm{a}}=293 \mathrm{~K}, U_{a}=20 \mathrm{~B}, t_{a}=20$ мин

[Fig. 1. $j_{a}(t)$ transients recorded during anodization of Ti, $\mathrm{Al}$ and $\mathrm{Ti}-40$ wt. $\% \mathrm{Al}$ samples in the $10 \% \mathrm{H}_{2} \mathrm{SO}_{4}+$ $\left.0.15 \% \operatorname{HF}\left(T_{\mathrm{a}}=293 \mathrm{~K}, U_{a}=20 \mathrm{~V}, t_{a}=20 \mathrm{~min}\right)\right]$ 

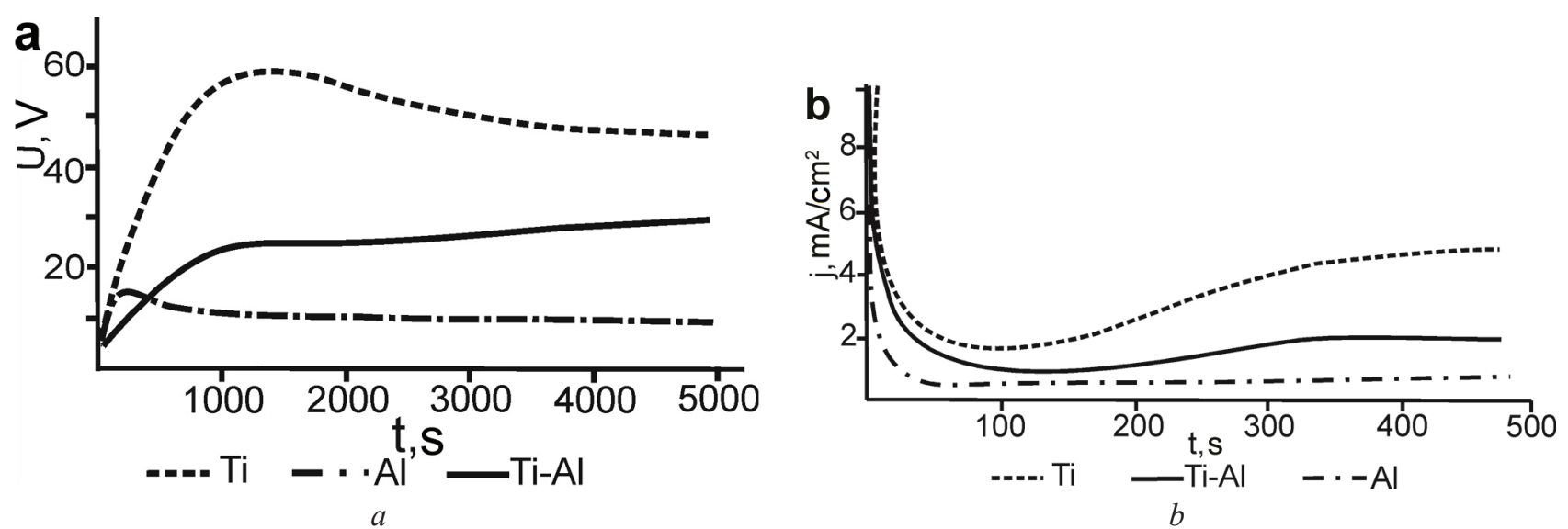

Рис. 2. Кривые $U_{a}(t)$, полученные при ГСР-анодировании $\left(j_{a}=1 \mathrm{~mA} / \mathrm{cm}^{2}, t_{a}=1.5\right.$ ч) образцов Al, Ti и Ti-40 вес. \% $\mathrm{Al}$ в $\mathrm{C}_{2} \mathrm{O}_{2} \mathrm{H}_{6}+0.25 \% \mathrm{NH}_{4} \mathrm{~F}(a)$; Кривые $j_{a}(t)$, полученных при ВCР - анодировании образцов в $\mathrm{C}_{2} \mathrm{O}_{2} \mathrm{H}_{6}+0.25 \%$ $\mathrm{NH}_{4} \mathrm{~F}, T_{\mathrm{a}}=293 \mathrm{~K}, t_{\mathrm{a}}=1.5 \mathrm{ч}: U_{a}^{\mathrm{Ti}}=41 \mathrm{~B}, U_{a}^{\mathrm{Al}}=10 \mathrm{~B}, U_{a}^{\mathrm{Ti}-\mathrm{Al}}=28 \mathrm{~B}(b)$. Показан начальный участок зависимости [Fig. 2. $U_{a}(\mathrm{t})(a)$ and $j_{a}(t)(b)$ transients recorded during anodization of $\mathrm{Al}$, Ti and Ti-40 wt. \% $\mathrm{Al}$ samples in the $\mathrm{C}_{2} \mathrm{O}_{2} \mathrm{H}_{6}$ $+0.25 \% \mathrm{NH}_{4} \mathrm{~F}\left(T_{\mathrm{a}}=293 \mathrm{~K}, t_{a}=90 \mathrm{~min}\right)(a)$ at $j_{a}=1 \mathrm{~mA} / \mathrm{cm}^{2} ;(b)$ at $U_{a}^{\mathrm{Al}}=41 \mathrm{~V}, U_{a}^{\mathrm{Al}}=10 \mathrm{~V}, U_{a}^{\mathrm{Ti}-\mathrm{Al}}=28 \mathrm{~V}$. Initial curves' parts are shown]
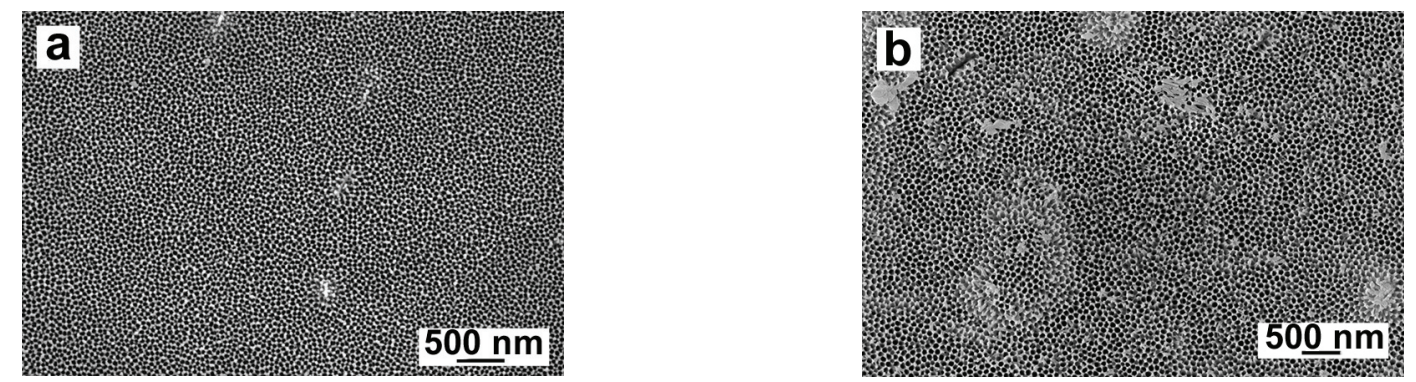

Рис. 3. СЭМ-изображения поверхности пористого слоя АОП, сформированной анодированием Тi-40 вес. \% Al в $10 \% \mathrm{H}_{2} \mathrm{SO}_{4}+0.15 \% \mathrm{HF}, U_{a}=20 \mathrm{~B}, 20$ мин $(a)$ и в $\mathrm{C}_{2} \mathrm{O}_{2} \mathrm{H}_{6}+0.25 \% \mathrm{NH}_{4} \mathrm{~F}, U_{a}=28$ В в течение 6 часов $(b)$

[Fig. 3. SEM images of the anodic oxide films formed on Ti-40 wt. $\% \mathrm{Al}$ after anodizing in: $(a)$ the $10 \% \mathrm{H}_{2} \mathrm{SO}_{4}+$ $0.15 \% \mathrm{HF}\left(U_{a}=20 \mathrm{~V}, t_{\mathrm{a}}=20 \mathrm{~min}\right)$ and $(b)$ the $\mathrm{C}_{2} \mathrm{O}_{2} \mathrm{H}_{6}+0.25 \% \mathrm{NH}_{4} \mathrm{~F}\left(U_{a}=28 \mathrm{~V}, t_{\mathrm{a}}=6\right.$ hours $\left.)\right]$

Тогда как (рис. $3 b$ ) анодирование в электролите Э-2 в течение 6 часов приводит к росту нанопористого оксидного слоя $\delta \sim 20 \mu \mathrm{m}$ и величиной $<d_{\text {п }}>=(65 \pm 15) \mathrm{nm}$.

Необходимо отметить, что анодирование в $10 \% \mathrm{H}_{2} \mathrm{SO}_{4}+0.15 \% \mathrm{HF}$ позволяет создать на поверхности образцов Ti-40 wt. \% Al AOП с открытыми наноразмерными порами. Тогда как для оксидных пленок, сформированных в Э-2, на отдельных участках поверхности регулярно-пористого слоя присутствует дополнительный, «дефектный» слой оксида, который ранее был выявлен при анодировании титана в том же электролите [18].

С помощью ЭДСА (табл. 1) обнаружено, что элементный состав оксидных пленок представлен в основном $\mathrm{Al}, \mathrm{Ti}, \mathrm{O}$, количественно соответствующих совокупности $\mathrm{TiO}_{2}$ и $\mathrm{Al}_{2} \mathrm{O}_{3}$ в примерно равном соотношении, что согласуется с данными $[13,14]$. Дополнительно обнаружено незначительное присутствие $\mathrm{F}$.

Методом РЭС (рис. 4) установлено, что в составе оксидных пленок присутствует ряд соединений, содержащих Ti, Al, O, F, С. Результаты РЭС свидетельствуют о присутствии в составе поверхностного слоя оксидных пленок, как диоксида титана $\left(\mathrm{TiO}_{2}\right)$, так и оксида алюминия $\left(\mathrm{Al}_{2} \mathrm{O}_{3}\right)$. Оценка соотношения оксидных фаз в поверхностном и приповерхностном слоях, показала, что оксиды, сформированные как в $10 \% \mathrm{H}_{2} \mathrm{SO}_{4}+0.15 \% \mathrm{HF}$, так и в $\mathrm{C}_{2} \mathrm{O}_{2} \mathrm{H}_{6}+0.25 \%$ $\mathrm{NH}_{4} \mathrm{~F}$, состоят из $\mathrm{TiO}_{2}$ и $\mathrm{Al}_{2} \mathrm{O}_{3}$ в соотношении 1:1, что согласуется с данными ЭДСА.

Методом РСА выявлено, что сформированные в обоих электролитах АОП являются рентгеноаморфными.

Таким образом, при анодировании в оптимальных условиях образцов $\gamma$-TiAl (группа I) 
Таблица 1. Результаты ЭДСА элементного состава для образцов группы I, подвергнутых анодированию: 1 в $10 \% \mathrm{H}_{2} \mathrm{SO}_{4}+0.15 \%$ HF в течение 20 мин при $U_{\mathrm{a}}=20 \mathrm{~B} ; 2-\mathrm{B}_{2} \mathrm{O}_{2} \mathrm{H}_{6}+0.25 \% \mathrm{NH}_{4} \mathrm{~F}$ при $U_{\text {а }}=28$ B в течение 6 ч

[Table 1. EDX data on the elemental composition of several regions on the sample of $1^{\text {st }}$ group after anodization: 1 - in an electrolyte with $10 \% \mathrm{H}_{2} \mathrm{SO}_{4}+0.15 \% \mathrm{HF}$ at $U_{\mathrm{a}}=20 \mathrm{~V}$ for $20 \mathrm{~min} ; 2$ - in an electrolyte with $\mathrm{C}_{2} \mathrm{O}_{2} \mathrm{H}_{6}+$ $0.25 \% \mathrm{NH}_{4} \mathrm{~F}$ at $U_{\mathrm{a}}=28 \mathrm{~V}$ for 6 hours]

\begin{tabular}{|c|c|c|c|c|c|}
\hline \multirow{3}{*}{$\begin{array}{c}\text { Образец } \\
\text { [Sample] }\end{array}$} & $\begin{array}{c}\text { Элемент } \\
\text { [Element] }\end{array}$ & \multicolumn{4}{|c|}{$\begin{array}{c}\text { Мacсовая доля элементов, вес. \% } \\
\text { [Weight fraction of elements, wt. \%] }\end{array}$} \\
\cline { 3 - 6 } & $\begin{array}{c}\text { Участок 1 } \\
\text { [Region 1] }\end{array}$ & $\begin{array}{c}\text { Участок 2 } \\
\text { [Region 2] }\end{array}$ & $\begin{array}{c}\text { Участок 3 } \\
\text { [Region 3] }\end{array}$ & $\begin{array}{c}\text { Участок 4 } \\
\text { [Region 4] }\end{array}$ \\
\hline \multirow{4}{*}{1} & $\mathrm{O}$ & 13.5 & 13.2 & 11.9 & 13.3 \\
\cline { 2 - 6 } & $\mathrm{F}$ & 3.7 & 3.7 & 3.2 & 3.6 \\
\cline { 2 - 6 } & $\mathrm{Al}$ & 33.5 & 32.7 & 35.3 & 33.4 \\
\cline { 2 - 6 } & $\mathrm{Ti}$ & 49.4 & 50.4 & 49.7 & 49.7 \\
\hline \multirow{3}{*}{2} & $\mathrm{C}$ & - & 3.6 & 5.1 & 7.0 \\
\cline { 2 - 6 } & $\mathrm{O}$ & 21.9 & 20.5 & 22.5 & 20.3 \\
\cline { 2 - 6 } & $\mathrm{F}$ & 14.6 & 13.7 & 17.6 & 13.4 \\
\cline { 2 - 6 } & $\mathrm{Al}$ & 23.0 & 21.8 & 21.5 & 21.5 \\
\cline { 2 - 6 } & $\mathrm{Ti}$ & 40.5 & 40.4 & 33.2 & 37.8 \\
\hline
\end{tabular}

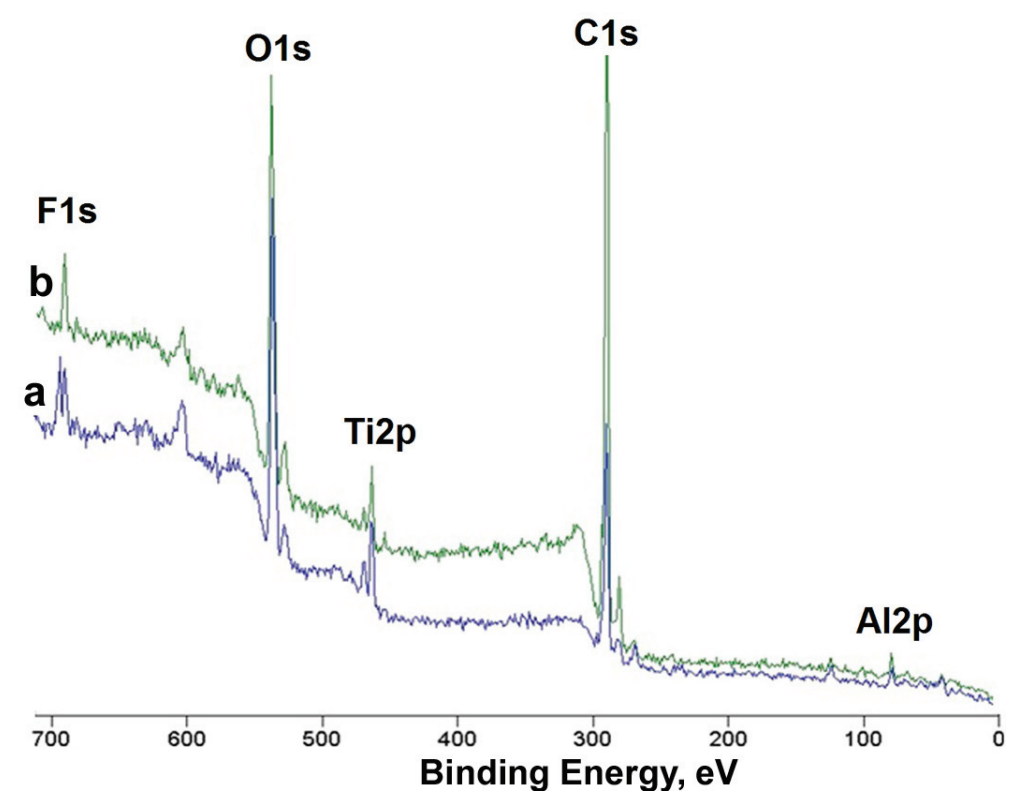

Рис. 4. Обзорные рентгеноэлектронные спектры для образцов группы I, анодированных в $10 \% \mathrm{H}_{2} \mathrm{SO}_{4}+0.15 \% \mathrm{HF}$ при $U_{a}=20 \mathrm{~B}, t_{a}=20$ мин (нижняя кривая) и в $\mathrm{C}_{2} \mathrm{O}_{2} \mathrm{H}_{6}+0.25 \% \mathrm{NH}_{4} \mathrm{~F}$ при $U_{a}=28 \mathrm{~B}$ в течение 6 часов (верхняя кривая)

[Fig. 4. XPS wide-scan spectrum of Ti-40 wt. \% Al samples ( $1^{\text {st }}$ group) after anodization in $(a)$ the $10 \% \mathrm{H}_{2} \mathrm{SO}_{4}+0.15 \%$ $\mathrm{HF}\left(U_{a}=20 \mathrm{~V}, t_{\mathrm{a}}=20 \mathrm{~min}\right)$ and $(b)$ the $\mathrm{C}_{2} \mathrm{O}_{2} \mathrm{H}_{6}+0.25 \% \mathrm{NH}_{4} \mathrm{~F}\left(U_{a}=28 \mathrm{~V}, t_{\mathrm{a}}=6\right.$ hours $\left.)\right]$

формируется нанопористая АОП гетерогенного состава, причем анодирование в водном фторсодержащем электролите позволяет создать на поверхности сплава рентгеноаморфную АОП с открытыми наноразмерными порами.

\section{Анодирование образцов $\gamma$-TiAl (группа II)}

Из полученных СЭМ-изображений поверхности образцов (как торцов, так и сломов) до анодиро- вания (рис. $5 a$ ) видно, что микрочастицы порошка имеют неправильную форму, а их размер находится в диапазоне от 1 до $20 \mu \mathrm{m}$, при преобладании мелкодисперсной фазы, хорошо соответствует полученным ранее данным [15]. С помощью ЭДСА (рис. $5 b$ ) показано, что состав исследуемых порошков, также как и образцов группы I, находится в области однофазного $\gamma$-TiAl, что было также подтверждено и результатами РСА. 

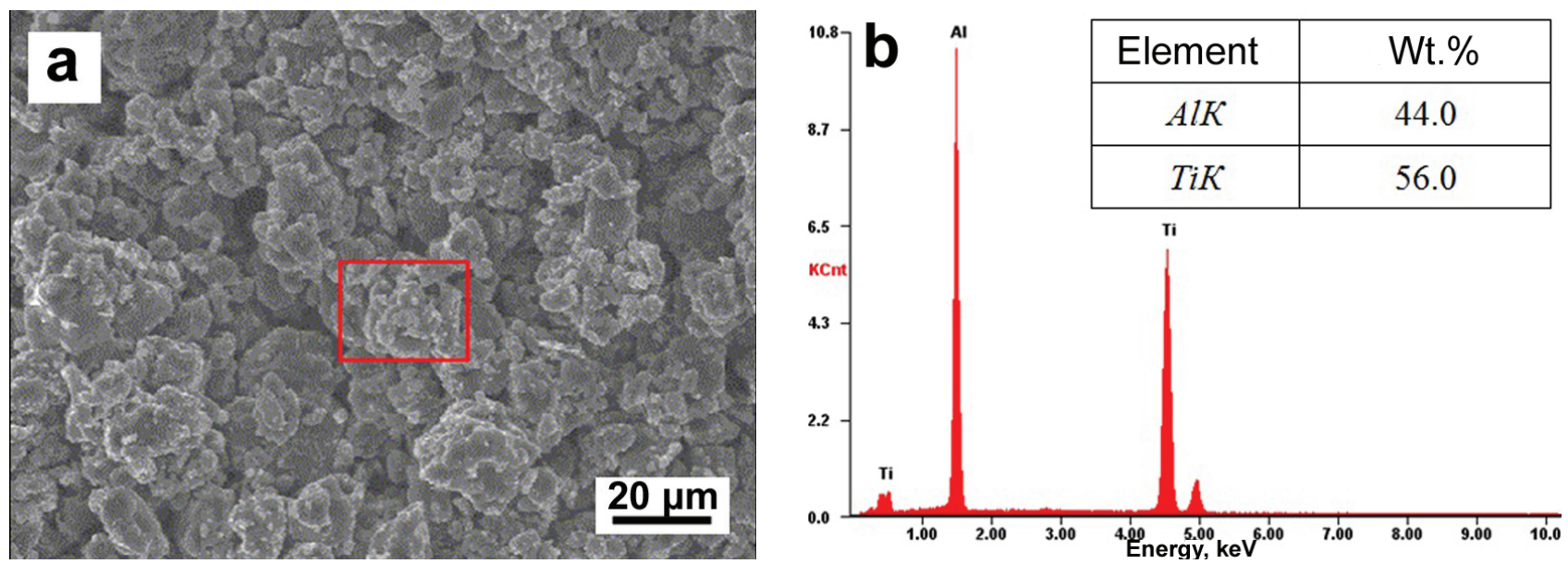

Рис. 5. СЭМ-изображение поверхности сплава Ті-40 вес. \% $\mathrm{Al}$ (группа II) до анодирования (a), ЭДС - спектр и состав анализируемого участка $(b)$

[Fig. 5. SEM image of the Ti- 40 wt. $\% \mathrm{Al}$ samples ( $2^{\text {nd }}$ group) before anodization $(a)$ and EDAX-spectrum of the analyzed area $(b)]$

Как было ранее установлено [15], для получения кинетических зависимостей, типичных для формирования самоорганизованных наноструктурированных оксидных пленок в $10 \% \mathrm{H}_{2} \mathrm{SO}_{4}+$ $0.15 \% \mathrm{HF}$, оптимальным является анодирование порошкового TiAl в вольтстатическом режиме при значении напряжения $U_{a}=15 \mathrm{~V}$ и гальваностатическом режиме при величине плотности тока $j_{a}=0.2 \mathrm{мA} / \mathrm{cm}^{2}$. При этом толщина формируемого оксида составляет $\delta \cong 300-350 \mathrm{~nm}$. Как видно из рис. $6 a, b$ после анодирования образцов группы II в электролите Э-1 в ГСР на поверхности частиц порошка четко проявляется нанопористый рельеф оксида. Статистический анализ дает величину эффективного диаметра пор $<d_{\text {п }}>=(70 \pm 10) \mathrm{nm}$, то есть после анодирования площадь поверхности образцов порошкового сплава Ti-40 wt. \% $\mathrm{Al}$ увеличивается примерно в 20 раз.

Экспериментально было обнаружено, что при анодировании образцов группы II в органических фторсодержащих электролитах формирование АОП происходит лишь в тонком поверхностном слое порошковых образцов, что, скорее всего, связано с высокой вязкостью раствора. При этом для АОП характерно присутствие неоднородного поверхностного слоя (толщиной до $500 \mathrm{~nm}$ ), в трещинах которого четко наблюдается регулярно-пористый рельеф оксида с размерами пор 40-80 nm (рис. 6c) [16]. Таким образом, для формирования АОП с открытыми нанопорами необходимо выполнять анодирование в водном фторсодержащем растворе.

Данные ЭДСА свидетельствуют, что оксидные пленки, сформированные в электролите Э-1, в основном состоят также из $\mathrm{TiO}_{2}$ и $\mathrm{Al}_{2} \mathrm{O}_{3}$ в соотноше- нии 1:1. Следует отметить, что в АОП, сформированных в Э-1, обнаружено незначительное содержание серы (до 3.9 wt. \%), а для АОП в Э-2 - присутствие фтора (7-26 wt. \%). Наличие в составе пленки серы и фтора может быть объяснено встраиванием анионов электролита в АОП при анодировании. Рентгенографическое исследование анодированных образцов группы II свидетельствует об их рентгеноаморфности.

Таким образом, анодирование в $10 \% \mathrm{H}_{2} \mathrm{SO}_{4}+$ $0.15 \% \mathrm{HF}$ в гальваностатическом режиме при $j_{a}=0.2 \mathrm{~mA} / \mathrm{cm}^{2}$, а также вольтстатическом режиме

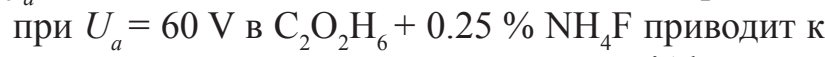
росту на поверхности порошкового $\gamma$-TiAl рентгеноаморфной оксидной пленки гетерогенного состава с размерами пор в диапазоне от 40 до $80 \mathrm{~nm}$, толщиной от 0.3 до $1 \mu \mathrm{m}$.

На основе результатов комплексного исследования структуры АОП на порошковом сплаве Ti-40 wt. \% Al, а также с учетом имеющихся представлений о строении термической оксидной пленки на поверхности алюминидов титана [28] и известных особенностях роста нанопористых и нанотрубчатых АОП на Ті при анодировании во фторсодержащих электролитах [27] была выдвинута модель строения гетерогенного анодной оксидной пленки, формируемой на поверхности Ті40 wt. \% Al [17]. В рамках этой модели стенки пор АОП представлены в основном $\mathrm{TiO}_{2}$, тогда как внешние границы ячеек состоят преимущественно из $\mathrm{Al}_{2} \mathrm{O}_{3}$. Используя предлагаемую модель, можно понять, как нанопористая мезоструктура сочетается с гетерогенностью состава оксида, представленного совокупностью оксидов титана и алюминия. 

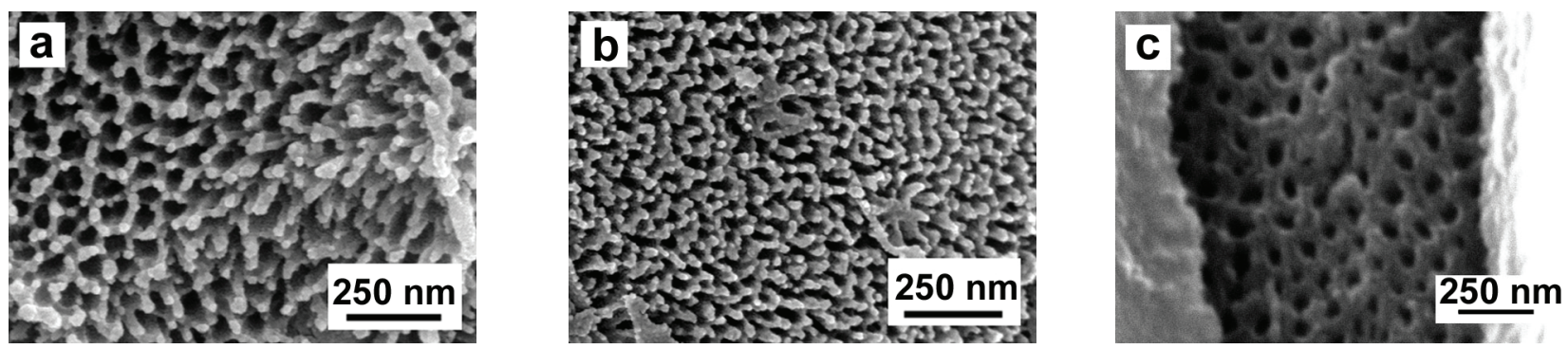

Рис. 6. СЭМ-изображения поверхности образцов порошкового сплава Ті-40 вес. \% Al после гальваностатического анодирования в $10 \% \mathrm{H}_{2} \mathrm{SO}_{4}+0.15 \% \mathrm{HF}$ при $T_{a}=293 \mathrm{~K}, j_{a}=0.2 \mathrm{MA} / \mathrm{cm}^{2}, t_{a}=85$ мин: торец $(a)$ и слом $(b)$, и после ВСР- анодирования в электролите $\mathrm{C}_{2} \mathrm{O}_{2} \mathrm{H}_{6}+0.25 \% \mathrm{NH}_{4} \mathrm{~F}$ при $U_{a}^{a}=60$ В в течение 30 мин (c).

[Fig. 6. SEM images of the end $(a)$ and cross-section $(b)$ of the Ti-40 wt. $\%$ Al powder samples ( $2^{\text {nd }}$ group) after anodization in the $10 \% \mathrm{H}_{2} \mathrm{SO}_{4}+0.15 \% \mathrm{HF}\left(T_{\mathrm{a}}=293 \mathrm{~K}, j_{\mathrm{a}}=0.2 \mathrm{~mA} / \mathrm{cm}^{2}, t_{\mathrm{a}}=85 \mathrm{~min}\right)$ as well as SEM image of the end $(c)$ of the Ti-40 wt. $\%$ Al powder]

\section{Оценка оптической ширины запрещенной зоны}

На первом этапе были получены спектры поглощения отделенных от подложки пленок НТАОТ $(\delta \approx 40 \mu \mathrm{m})$. Обнаружено (рис. $7 a)$, что на кривых $A(\lambda)$ наблюдается спад оптической плотности в интервале длин волн от 330 до $380 \mathrm{~nm}$. Значение длины волны края собственного поглощения равно $\lambda_{\text {гр }}=(365 \pm 10) \mathrm{nm}$, что соответствует величине $E_{\mathrm{g}}=(3.40 \pm 0.10) \mathrm{eV}$, которая хорошо согласуется с данными [29].

Для анодированного в $10 \% \mathrm{H}_{2} \mathrm{SO}_{4}+0.15 \% \mathrm{HF}$ порошка TiAl спад оптической плотности наблюдается в области длин волн от 400 до $460 \mathrm{~nm}$ (рис. 7b). Соответственно, значение $\lambda_{\text {гр }}=(495 \pm 15) \mathrm{nm}$ принадлежит голубой области видимого спектра и величина $E_{\mathrm{g}}$ в этом случае $E_{\mathrm{g}}=(2.50 \pm 0.07) \mathrm{eV}$.

Уменьшение значения $E_{\mathrm{g}}$ титаноксидной компоненты аморфного оксида, сформированного на порошках Ti-40 wt. \% Al, по сравнению с нанотруб-

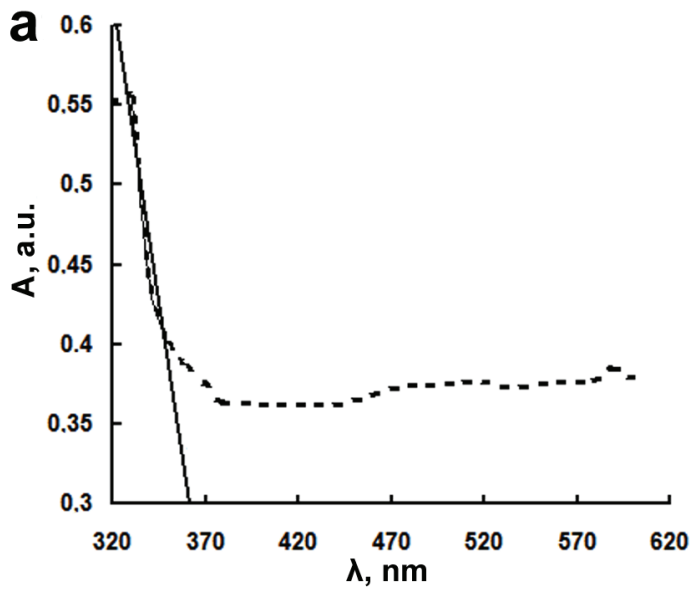

чатым $\mathrm{TiO}_{2}$, скорее всего, обусловлено влиянием присутствующего в составе оксидной пленки $\mathrm{Al}_{2} \mathrm{O}_{3}$. Как уже указывалось, наличие $\mathrm{Al}_{2} \mathrm{O}_{3}$ создает возможности дополнительных межзонных переходов электронов и дырок, что способствует сдвигу края поглощения в длинноволновую область [7].

\section{Оценка фотокаталитической активности}

На зависимостях $A(\lambda)$ раствора метилового оранжевого (рис. 8) после засветки электромагнитным излучением видимого диапазона в присутствии микрочастиц анодированного порошка наблюдался абсорбционный пик при $\lambda \approx 464 \mathrm{~nm}$, соответствующий водному раствору МО [24]. Дополнительных пиков поглощения в спектре в процессе всего времени засветки не было зарегистрировано, что указывает на отсутствие образования побочных продуктов в ходе процесса деградации красителя [25].

Как видно из рис. 8 , после семичасовой засветки видимым светом наблюдается уменьшение оптической плотности раствора $\mathrm{MO}$ от $C_{\mathrm{o}}=5 \mathrm{mg} / \mathrm{l}$ до

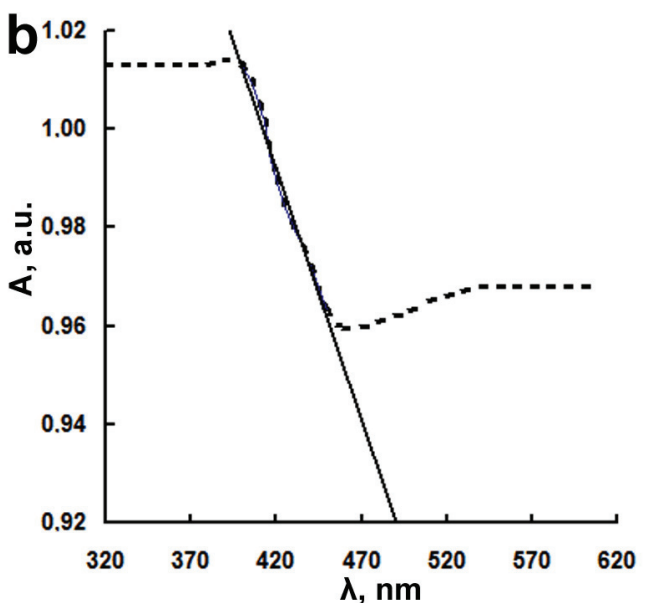

Рис. 7. Зависимости $\mathrm{A}(\lambda)$ для отделенных пленок НТАОТ $(a)$ и анодированных образцов Ті-40вес.\%Al группы II $(b)$ [Fig. 7. Absorbance spectra of nanotubular anodic $\mathrm{TiO}_{2}(a)$ and anodized Ti-40 wt. \% Al powder $(b)$ ] 


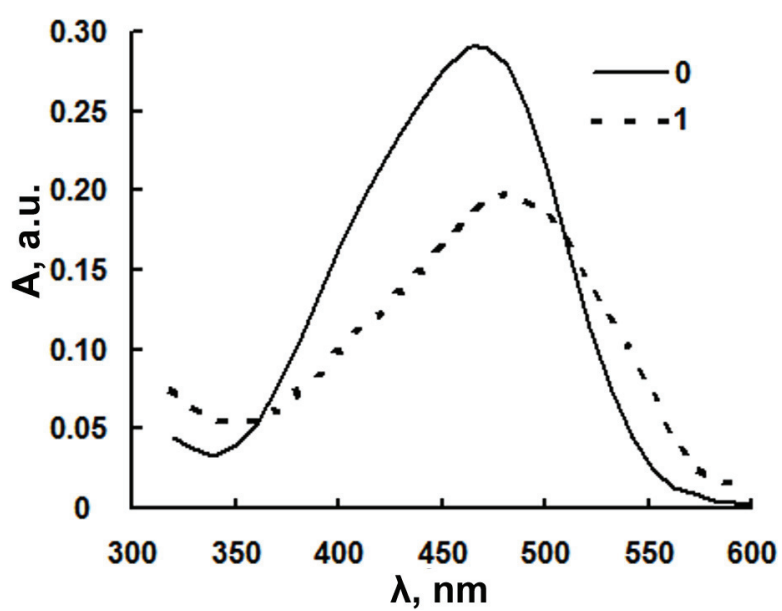

Рис. 8. Зависимости $A(\lambda)$ для раствора МО до (кривая 0 ) и после семичасовой засветки излучением в видимом диапазоне в присутствии образцов анодированного в $10 \% \mathrm{H}_{2} \mathrm{SO}_{4}+0.15 \% \mathrm{HF}$ порошка сплава Ti-40 вес. \% $\mathrm{Al}$ (кривая 1)

[Fig. 8. Absorption spectra of MO (curve 0) and $\mathrm{MO}$ with addition of anodized Ti-40 wt. \% Al powder (curve 1) after visible irradiation in 7 hours]

$C_{\mathrm{x}} \approx 3.4 \mathrm{mg} / 1$. То есть имеет место $30 \%$-ная конверсия МО в присутствии анодированного порошка Ti-40 wt. \% Al. Следует отметить, что после засветки происходит смещение максимума зависимости $A(\lambda)$ в сторону больших длин волн (с 464 до $490 \mathrm{~nm}$ ), что может быть связано с уменьшением $\mathrm{pH}$ (с 5.2 до 3) раствора под действием излучения, которое, в свою очередь, происходит из-за изменения карбонатной жесткости кН из-за увеличения содержания $\mathrm{CO}_{2}$ в растворе $\mathrm{MO}$.

Таким образом, в результате оценки фотокаталитической активности в реакции разложения МО установлено, что нанопористые анодно-оксидные пленки, полученные анодирование порошкового сплава Ti-40 wt. \% Al, являются фотокаталитически активными в расширенном до видимого спектральном диапазоне облучения. Полученные результаты демонстрируют перспективность дальнейшего более детального исследования фотокаталитической активности порошка алюминида титана, модифицированного анодированием во фторсодержащем электролите.

\section{ЗАКЛЮЧЕНИЕ}

В рамках работы выполнено обобщение результатов исследований анодирования алюминида титана (Ti-40 wt. \% Al) во фторсодержащих электролитах.

С применением комплекса методов установлено, что анодирование образцов группы I в
$10 \% \mathrm{H}_{2} \mathrm{SO}_{4}+0.15 \% \mathrm{HF}$ при напряжении $U_{a}=20 \mathrm{~V}$, $t=20 \mathrm{~min}$, а в $\mathrm{C}_{2} \mathrm{O}_{2} \mathrm{H}_{6}+0.25 \% \mathrm{NH}_{4} \mathrm{~F}$ при $U_{a}=28 \mathrm{~V}$ формирует на поверхности Ti-40 wt. \% Al рентгеноаморфные самоорганизованные оксидные пленки гетерогенного состава, включающего $\mathrm{TiO}_{2}$ и $\mathrm{Al}_{2} \mathrm{O}_{3}$.

Показано, что анодирование порошкового сплава Ti- 40 wt. \% $\mathrm{Al}$ в $10 \% \mathrm{H}_{2} \mathrm{SO}_{4}+0.15 \% \mathrm{HF}$ в гальваностатическом режиме при $j_{a}=0.2 \mathrm{~mA} / \mathrm{cm}^{2}$, а также

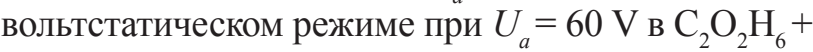
$0.25 \% \mathrm{NH}_{4} \mathrm{~F}$ приводит к росту на поверхности порошкового $\gamma$-TiAl рентгеноаморфной оксидной пленки гетерогенного состава с размерами пор в диапазоне от 40 до $80 \mathrm{~nm}$, толщиной от 0.3 до $1 \mu \mathrm{m}$.

Установлен факт уменьшения оптической ширины запрещенной зоны $\left(E_{g} \sim 2.5 \mathrm{eV}\right)$ для рентгеноаморфного оксида гетерогенного состава, сформированного на порошковом сплаве Ti-40 wt. \% Al, по сравнению с соответствующей величиной, характерной для диоксида титана $\left(E_{g} \sim 3.4 \mathrm{eV}\right)$.

Показано, что гетерогенные нанопористые оксидные пленки, полученные на порошковом сплаве Ti-40 wt. \% Al, проявляют фотокаталитическую активность под действием электромагнитного излучения видимого диапазона.

Таким образом, результаты работы свидетельствуют о перспективности применения анодного наноструктурирования порошков Ti-40 wt. \% Al для получения фотокаталитически активных материалов с расширенным до видимого света спектральным диапазоном поглощения.

\section{КОНФЛИКТ ИНТЕРЕСОВ}

Авторы декларируют отсутствие явных и потенциальных конфликтов интересов, связанных с публикацией настоящей статьи.

\section{СПИСОК ЛИТЕРАТУРЫ}

1. Wang Y., Ma X., Li H., Yin S., Sato T. // Advanced Catalytic materials - Photocatalysis and Other Current Trends, 2016, vol. 12, pp. 337-357. DOI: 10.5772/61864

2. Hashimoto K., Irie H., Fujishima A. // Japanese Journal of Applied Physics, 2005, vol. 44, № 12, pp. 82698285. DOI: $10.1143 /$ JJAP.44.8269

3. Uddin Md.T., Engg M. Sc. Diss. ... Dr. Rer. Nat. Technical University of Darmstadt, 2014, 222 p. Available at: https://d-nb.info/1061050335/04 (accessed 28.11.2018)

4. Batzill M. // Energy Environ. Sci., 2011, vol. 4, pp. 3275-3286. DOI: 10.1039/C1EE01577J

5. Marschall R. // Adv. Funct. Mater., 2014. vol. 24. pp. 2421-2440. DOI: 10.1002/adfm.201303214

6. Ghicov A., Schmuki P. // Chem. Commun., 2009, pp. 2791-2808. DOI: 10.1039/B822726H 
7. Li F., Zhao Y., Hao Y., Wang X., Liu R., Zhao D., Chen D. // Journal of Hazardous Materials, 2012, vol. 239240. pp. 118-127. DOI: 10.1016/j.jhazmat.2012.08.016

8. Morris S. M., Horton J. A., Jaroniec M. // Micropor. Mesopor. Mater., 2010, vol. 128, pp. 180-186. DOI: 10.1016/j.micromeso.2009.08.018

9. Ahmed M. A., Abdel-Messih M. F. // Journal of Alloys and Compounds, 2011, vol. 509, pp. 2154-2159. DOI: 10.1016/j.jallcom.2010.10.172

10. Pakmehr M., Nourmohammadi A., Ghashang M., Saffar-Teluri A. // Journal of Particle Science and Technology, 2015, pp. 31-38. DOI: 10.22104/JPST.2015.76

11. Pei J., Ma W., Li R., Li Y., Du H. // Journal of Chemistry, 2015, pp. 1-7. DOI: 10.1155/2015/806568

12. Ильин А. А., Колачев Б. А., Полькин И. С. Tuтановые сплавы. Состав, структура, свойства. М.: ВИЛС-МАТИ, 2009, 520 с.

13. Tsuchiya H., Berger S., Macak J. M., Ghicov A., Schmuki P. // Electrochem. Comm., 2007, vol. 9, pp. $2397-$ 2402. DOI: 10.1016/j.elecom.2007.07.013

14. Berger S., Tsuchiya H., Schmuki P. // Chem. Mater., 2008, vol. 20, pp. 3245-3247. DOI: 10.1021/cm8004024

15. Степанова К. В., Яковлева Н. М., Кокатев А. Н., Петтерссон Х. // Уч. зап. ПетрГУ. Серия Естественные и технические науки, 2015, т. 147, № 2, с. 81-86.

16. Степанова К. В., Яковлева Н. М., Кокатев А. Н., Петтерссон Х. // Поверхность. Рентгеновские, синхротронные и нейтронные исследования, 2016, № 9, с. 54-62. DOI: $10.1134 / \mathrm{S} 102745101605013 \mathrm{X}$

17. Степанова К. В. Дисс. ... канд. тех. наук. Петрозаводск, 2016, 162 с.

18. Яковлева Н. М., Кокатев А. Н., Степанова К. В., Яковлев А. Н., Чупахина Е. А., Шульга А. М., Васильев С. Г. // Конденсированные среды и межфазные границы, 2016, т. 18, № 1, с. 6-27. URL: http://www.kcmf. vsu.ru/resources/t_18_1_2016_001.pdf

19. Кокатев А. Н. Дисс. ... канд. тех. наук. Петрозаводск, 2013, $170 \mathrm{c}$.

20. Савченко О. И., Яковлева Н. М., Яковлев А. Н., Кокатев А. Н., Петтерссон Х. // Конденсированные среды и межфазные гранииы, 2012, т. 14, № 2, с. 243-249. URL: http://www.kcmf.vsu.ru/resources/t_14_2_2012_018. pdf

21. Canulescu S., Rechendorff K., Borca C. N., Jones N. C., Bordo K., Schou J., Pleth Nielsen L., Hoffmann S. V., Ambat R. // Applied Physics Letters, 2014, vol. 104, pp. 121910(1-4). DOI: 10.1063/1.4866901

22. Chen C., Liu J., Liu P., Yu B. // Advances in Chemical Engineering and Science, 2011, vol. 1, pp. 9-14. DOI: $10.4236 /$ aces.2011.11002

23. Rashed M. N., El-Amin A. A. // International Journal of Physical Sciences, 2007, vol. 2 (3), pp. 073-081. Available at http://www.academicjournals.org/IJPS (accessed 28.11.2018)

24. Иванов В. М., Цепков М. Г., Фигуровская В. Н. // Вестник Московского университета. Серия 2: Химия, 2010, т. 51, № 6, c. 445-449.

25. Scuderi V., Impellizzeri G., Romano L., Scuderi M., Nicotra G., Bergum K., Irrera A., Svensson B. G., Privitera V. // Nanoscale Research Letters, 2014, vol. 9, pp. 458464. DOI:10.1186/1556-276X-9-458

26. AbdElmoula M. Diss. ... Dr. Philosophy. Boston, 2011, 275 p.

27. Lee K., Mazare A., Schmuki P. // Chem. Rev., 2014, vol. 114, pp. 9385-9454. DOI: 10.1021/cr500061m

28. Leyens C., Peters M. Titanium and Titanium Alloys. Fundamentals and Applications. Weinheim: WILEY-VCH Verlag GmbH \& Co. KGaA, 2003, 532 p.

29. Colmenares J. C., Luque R. // Chem. Soc. Rev., 2014, vol. 43, pp. 765-778. DOI: 10.1039/c3cs60262a

\title{
THE STRUCTURE AND PROPERTIES OF NANOPOROUS ANODIC OXIDE FILMS ON TITANIUM ALUMINIDE
}

\author{
(C) 2019 K. V. Stepanova*1, N. M. Yakovleva ${ }^{1}$, A. N. Kokatev ${ }^{1}$, and H. Pettersson ${ }^{2}$ \\ ${ }^{1}$ Petrozavodsk State University \\ 33, Lenin ave., 185910 Petrozavodsk, Republic of Karelia, Russian Federation \\ ${ }^{2}$ Halmstad University \\ SE-302-50 Halmstad, Sweden
}

\begin{abstract}
Purpose. The paper presents a structural analysis of nanoporous oxide films formed by anodizing rTiAl (Ti-40 wt. \%Al) samples in fluoride containing water and waterless electrolytes.
\end{abstract}

$\triangle$ Stepanova Kristina V, e-mail: lady.cristin4ik@yandex.ru 
Methods and methodology. Two groups of samples produced from (1) ingots and (2) sintered powder were used for anodizing. X-ray diffraction, X-ray electron spectroscopy, and scanning electron microscopy were used to analyse the structure of the films. The band gap values of anodized powder samples were estimated based on their UV-vis absorption spectra. The reaction of degradation of methyl orange under UV-vis irradiation was used to examine the photocatalytic activity of anodized TiAl powder.

Results. Anodizing performed under optimal conditions in a $10 \% \mathrm{H}_{2} \mathrm{SO}_{4}+0.15 \% \mathrm{HF}$ water electrolyte for both groups of samples results in the formation of self-organized nanoporous films of about $350 \mathrm{~nm}$ thickness with effective pore diameter $\left\langle d_{\mathrm{p}}\right\rangle=(70 \pm 10) \mathrm{nm}$. All the studied oxide films are heterogeneous, consist mostly of $\mathrm{TiO}_{2}: \mathrm{Al}_{2} \mathrm{O}_{3}$ in a ratio of approximately $1: 1$, and have an X-ray amorphous structure. The optical band gap value of anodized powders determined by their UV absorption was $E_{\mathrm{g}} \sim 2.5 \mathrm{eV}$. It is much less than $E_{\mathrm{g}}$ of nanotubular titanium dioxide $\left(E_{\mathrm{g}} \sim 3.4 \mathrm{eV}\right)$. The study also found that the concentration of methyl orange decreases under visible light irradiation in the presence of anodized TiAl powder.

Conclusion. Photocatalytic activity of the developed heterogeneous films might be initiated by the visible light irradiation $(\lambda \sim 480-510 \mathrm{~nm})$. In other words, the new composite "TiAl powder $/ \mathrm{TiO}_{2}-\mathrm{Al}_{2} \mathrm{O}_{3}$ nanoporous oxide" exhibits activity under the visible light radiation which results in the photocatalytic degradation of methyl orange. The obtained results can be successfully used for the production of new powder nanomaterials which show photocatalytic activity under visible light irradiation.

Keywords: anodizing, nanoporous, oxide films, powder alloy, titanium aluminide, heterogeneous, photocatalytic activity.

\section{CONFLICT OF INTEREST}

The authors declare the absence of obvious and potential conflicts of interest related to the publication of this article.

\section{REFERENCES}

1. Wang Y., Ma X., Li H., Yin S., Sato T. Advanced Catalytic materials - Photocatalysis and Other Current Trends, 2016, vol. 12, pp. 337-357. DOI: 10.5772/61864

2. Hashimoto K., Irie H., Fujishima A. Japanese Journal of Applied Physics, 2005, vol. 44, no. 12, pp. 8269-8285. DOI: $10.1143 /$ JJAP.44.8269

3. Uddin Md.T., Engg M. Sc. Diss. ... Dr. Rer. Nat. Technical University of Darmstadt, 2014, 222 p. URL: https://d-nb.info/1061050335/04 (accessed 28.11.2018)

4. Batzill M. Energy Environ. Sci., 2011, vol. 4, pp. 3275-3286. DOI: 10.1039/C1EE01577J

5. Marschall R. Adv. Funct. Mater., 2014. vol. 24. pp. 2421-2440. DOI: 10.1002/adfm.201303214

6. Ghicov A., Schmuki P. Chem. Commun., 2009, pp. 2791-2808. DOI: 10.1039/B822726H

7. Li F., Zhao Y., Hao Y., Wang X., Liu R., Zhao D., Chen D. Journal of Hazardous Materials, 2012, vol. 239240. pp. 118-127. DOI: 10.1016/j.jhazmat.2012.08.016

8. Morris S. M., Horton J. A., Jaroniec M. Micropor. Mesopor. Mater., 2010, vol. 128, pp. 180-186. DOI: 10.1016/j.micromeso.2009.08.018

9. Ahmed M. A., Abdel-Messih M. F. Journal of Alloys and Compounds, 2011, vol. 509, pp. 2154-2159. DOI: 10.1016/j.jallcom.2010.10.172

10. Pakmehr M., Nourmohammadi A., Ghashang M., Saffar-Teluri A. Journal of Particle Science and Technology, 2015, pp. 31-38. DOI: 10.22104/JPST.2015.76
11. Pei J., Ma W., Li R., Li Y., Du H. Journal of Chemistry, 2015, pp. 1-7. DOI:10.1155/2015/806568

12. Il'in A. A., Kolachev B. A., Pol'kin I. S. Titanovye splavy. sostav, struktura, svoistva [Titanium alloys. Composition, structure, properties]. Moscow, VILS-MATI Publ., 2009, 520 p. (in Russ.)

13. Tsuchiya H., Berger S., Macak J.M., Ghicov A., Schmuki P. Electrochem. Comm., 2007, vol. 9, pp. 23972402. DOI: 10.1016/j.elecom.2007.07.013

14. Berger S., Tsuchiya H., Schmuki P. Chem. Mater., 2008 , vol. 20 , pp. $3245-3247$. DOI: $10.1021 / \mathrm{cm} 8004024$

15. Stepanova K. V., Yakovleva N. M., Kokatev A. N., Pettersson Kh. Uch.zap. PetrGU. Seriya Estestvennye $i$ tekhnicheskie nauki, 2015, vol. 147, no. 2, pp. 81-86. (in Russ.)

16. Stepanova K. V., Yakovleva N. M., Kokatev A. N., Pettersson H. Journal of Surface Investigation. X-ray, Synchrotron and Neutron Techniques, 2016, vol. 10, no. 5, pp. 933-941. DOI: 10.1134/S102745101605013X

17. Stepanova K. V. Diss. kand. tekh. nauk. Petrozavodsk, 2016, 162 p. (in Russ.)

18. Yakovleva N. M., Kokatev A. N., Chupakhina E. A., Stepanova K. V., Yakovlev A. N., Vasil'ev S. G., Shul'ga A. M. Condensed Matter and Interphases, 2016, vol. 18, no. 1, pp. 6-27. URL: http://www.kcmf.vsu.ru/resources/t_18_1_ 2016_001.pdf (in Russ.)

19. Kokatev A. N. Diss. kand. tekh. nauk. Petrozavodsk, 2013, $170 \mathrm{p}$.

20. Savchenko O. I., Yakovleva N. M., Yakovlev A. N., Kokatev A. N., Pettersson Kh. Condensed Matter and Interphases, 2012, vol. 14, no. 2, pp. 243-249. URL: http://www. kcmf.vsu.ru/resources/t_14_2_2012_018.pdf(in Russ.)

21. Canulescu S., Rechendorff K., Borca C. N., Jones N. C., Bordo K., Schou J., Pleth Nielsen L., Hoff- 
mann S. V., Ambat R. Applied Physics Letters, 2014, vol. 104, pp. 121910(1-4). DOI: 10.1063/1.4866901

22. Chen C., Liu J., Liu P., Yu B. Advances in Chemical Engineering and Science, 2011, vol. 1, pp. 9-14. DOI: 10.4236/aces.2011.11002

23. Rashed M. N., El-Amin A. A. International Journal of Physical Sciences, 2007, vol. 2 (3), pp. 073-081. URL: http://www.academicjournals.org/IJPS (accessed 28.11.2018)

24. Ivanov V. M., Tsepkov M. G., Figurovskaya V. N. Vestnik Moskovskogo universiteta. Seriya 2: Khimiya [Moscow University Chemistry Bulletin], 2010, vol. 65, no. 6, pp. 370-373. DOI: DOI: 10.3103/S0027131410060076
25. Scuderi V., Impellizzeri G., Romano L., Scuderi M., Nicotra G., Bergum K., Irrera A., Svensson B.G., Privitera V. Nanoscale Research Letters, 2014, vol. 9, pp. 458-464. DOI:10.1186/1556-276X-9-458

26. AbdElmoula M. Diss. Dr. Philosophy. Boston, 2011, $275 \mathrm{p}$.

27. Lee K., Mazare A., Schmuki P. Chem. Rev., 2014, vol. 114, pp. 9385-9454. DOI: 10.1021/cr500061m

28. Leyens C., Peters M. Titanium and Titanium Alloys. Fundamentals and Applications. Weinheim: WILEY-VCH Verlag GmbH \& Co. KGaA, 2003, 532 p.

29. Colmenares J. C., Luque R. Chem. Soc. Rev., 2014, vol. 43, pp. 765-778. DOI: 10.1039/c3cs60262a.
Степанова Кристина Вячеславовна - к. т. н., инженер, Петрозаводский государственный университет, Петрозаводск, Республика Карелия, Российская Федерация; e-mail: lady.cristin4ik@yandex. ru. ORCID iD 0000-0002-4737-497X

Яковлева Наталья Михайловна - д. ф.-м. н., профессор, Петрозаводский государственный университет, Петрозаводск, Республика Карелия, Российская Федерация; e-mail: nmyakov@petrsu.ru. ORCID iD 0000-0003-4294-0183

Кокатев Александр Николаевич - к. т. н., инженер, Петрозаводский государственный университет, Петрозаводск, Республика Карелия, Российская Федерация; e-mail: nelan-oksid@bk.ru. ORCID iD 0000-0002-9449-1482.

Хокан Петтерссон - профессор, зав. лабораторией математики, физики и электротехники, университет г. Хальмштад, Швеция; e-mail: Hakan.Pettersson@hh.se.
Stepanova Kristina V. - Cand. Sci. (Tech.), Engineer, Petrozavodsk State University, Petrozavodsk, Republic of Karelia, Russian Federation; email: lady. cristin4ik@yandex.ru. ORCID iD 0000-0002-4737497X

Yakovleva Natalia M. - Dr. Sci. (Phys.), Full Professor, Petrozavodsk State University, Petrozavodsk, Republic of Karelia, Russian Federation; e-mail: nmyakov@petrsu.ru. ORCID iD 0000-0003-42940183

Kokatev Alexander N. - Cand. Sci. (Tech.), Engineer, Petrozavodsk State University; Petrozavodsk, Republic of Karelia, Russian Federation; e-mail: nelan-oksid@bk.ru. ORCID iD 0000-0002-94491482.

Pettersson Hekan - Professor, Halmstad University, Halmstad, Sweden; e-mail: Hakan.Pettersson@ hh.se 